Cita bibliográfica: Sánchez Jiménez, M. Á., Fernández Alles, M. F. y Mier-Terán Franco, J. J. (2020). El uso y la importancia de las redes sociales en el sector hotelero desde la perspectiva de los responsables de su gestión. Investigaciones Turísticas (20), pp. 50-78. https://doi.org/10.14198/INTURI2020.20.03

\title{
El uso y la importancia de las redes sociales en el sector hotelero desde la perspectiva de los responsables de su gestión
}

\section{The use and importance of social networks in the hotel sector from the perspective of those responsible for their management}

Miguel Ángel Sánchez Jiménez iD, Universidad de Cádiz, España miguelangel.sanchez@uca.es

María Teresa Fernández Alles iD, Universidad de Cádiz, España teresa.alles@uca.es

Juan José Mier-Terán Franco iD, Universidad de Cádiz, España juanjose.mier-teran@uca.es

\section{RESUMEN}

Cuando comenzó a percibirse las redes sociales como un factor importante que podía afectar al negocio empresarial muchas organizaciones la han tenido en cuenta para el desarrollo de su gestión. Esta utilización de las redes sociales es especialmente relevante en las empresas turísticas ya que dependen en gran medida de la opinión y la experiencia del cliente. Así, en este estudio se ha planteado conocer el uso y la importancia de las redes sociales en el sector hotelero a través de una investigación cualitativa mediante entrevistas a diez responsables de la gestión de redes sociales de establecimientos hoteleros. De esta manera se ha tenido en cuenta el marco teórico para obtener las categorías y realizar las preguntas de investigación. Posteriormente, mediante un análisis de contenido a través del software Nvivo 11, se obtuvo inductivamente subcategorías con características comunes que se dividieron en unidades de análisis mediante la codificación de los datos, facilitando así la interpretación de la información. En los resultados los gestores de redes sociales entrevistados destacaron la importancia que tienen los medios sociales en el sector hotelero para relacionarse e interactuar con los usuarios, de manera que consideran esencial el planteamiento de objetivos propios para este ámbito y el desarrollo de estrategias dependiendo de las redes sociales en las que vayan a intervenir. Así, las ventajas más destacadas son la visibilidad, la facilidad de acceder a la información y la posibilidad de tener una mejor comunicación, relación e interacción con los usuarios. 
Palabras claves: Redes sociales; gestión; sector hotelero; marketing; estrategia.

\section{ABSTRACT}

When it started to become apparent how much social networks affect business, many organizations began to take them into account in the development of their management. The use of social networks is especially relevant in tourism companies since they largely depend on the opinion and experience of the client. Thus, this study seeks to gain a knowledge about the use and importance of social networks in the hotel sector through qualitative research based on interviews with the social network managers of ten hotel establishments. The theoretical framework has been taken into account to obtain the different categories and elaborate the research questions. Subsequently, through a content analysis using the Nvivo 11 software, subcategories with common characteristics were inductively obtained and divided into units of analysis by coding the data, thus facilitating the interpretation of the information. In the results, the social network managers interviewed stressed the importance of social media in the hotel sector to interact and interact with users. Therefore, they consider it essential to set their own goals for this area and to develop strategies depending on the social networks in which they intervene. The most prominent advantages identified are visibility, the ease of accessing information and the possibility of having a better communication, relationship and interaction with users.

Keywords: Social networks; managers; hotel sector; marketing; strategy.

\section{INTRODUCCIÓN}

En el sector turístico las redes sociales han tenido un gran impacto en la forma en que las personas buscan y comparten información, e incluso toman decisiones sobre su destino. Además, las características del sector turístico hacen que su impacto a través de las redes sociales sea especialmente importante: como sector de servicios, vende productos intangibles que son característicamente inseparables, perecederos y heterogéneos, haciendo del proceso de comunicación un elemento vital de la oferta (Chen y Wu, 2019).

Los blogs, las redes sociales, los sistemas de recomendación, la integración de contenido, el audio y el video contribuyen al proceso de anticipación, experiencia y recreación de un viaje turístico (Caro et al., 2015). Las organizaciones pueden usar estos canales en línea para mejorar las experiencias de los usuarios, lo que en última instancia conduce al logro de la lealtad del cliente a largo plazo (Lemon y Verhoef, 2016; Leva y Ziliani, 2018). Las redes sociales han complementado e incluso reemplazado las fuentes tradicionales de información turística, como guías de viaje, libros, periódicos y revistas. Estos nuevos canales de comunicación brindan a los usuarios información sobre viajes y les permiten compartir sus experiencias de manera interactiva. Los consumidores ahora ven las redes sociales como una fuente de información mucho más confiable sobre productos y servicios que los canales de comunicación de marketing patrocinados por corporaciones, que tradicionalmente han servido como medios para promocionar bienes y servicios (Barcelos et al., 2019). 
Por lo tanto, las redes sociales han revolucionado la industria del turismo y la hostelería y han permitido a los clientes facilitar el intercambio fácil de comentarios y evaluaciones de lugares, destinos y experiencias turísticas (Huang et al., 2017). El escenario creado por Internet y las tecnologías de la información y la comunicación (TIC) ha favorecido indudablemente la incorporación de diversos recursos y procesos que generan información sobre las preferencias de consumo turístico, permitiendo a los países y operadores responder de manera más efectiva a las necesidades reveladas y, por lo tanto, mejorar la competitividad de la oferta turística de los destinos (Arroyo, 2016). Actualmente, las revisiones de hoteles en línea representan una fuente importante de datos que afectan el comportamiento y las elecciones de los clientes. Dado esto, los hoteles pueden monitorear efectivamente a los turistas a través de una revisión en línea obteniendo información de cómo los viajeros buscan, descubren y evalúan a los proveedores turísticos y sus productos y servicios (Ahani et al., 2019). Es importante tener en cuenta que las comunicaciones en el ámbito digital se extienden más rápido que cualquier otra forma de comunicación. Ya no es necesario que las personas esperen o se comuniquen físicamente para comprender la situación real del hotel en el que desean alojarse con fines turísticos (Ristova y Dimitrov, 2019). Por lo tanto, no puede haber ninguna duda sobre el impacto de las redes sociales en el ámbito de la hospitalidad.

Sin embargo, si bien el uso de las redes sociales se ha convertido en una importante herramienta de marketing para el sector turístico, falta por profundizar cuestiones sobre como las marcas turísticas utilizan las redes sociales, cuál es su importancia en este contexto y cuáles son las perspectivas de futuro.

De esta manera, el objetivo de este estudio es conocer el uso y la utilización de las redes sociales en el sector hotelero a través de una investigación cualitativa mediante entrevistas a los responsables de la gestión de las redes sociales de establecimientos hoteleros. Así, se pretende conocer cuáles son los objetivos y las estrategias que plantean, la gestión que realizan, el impacto y la relevancia que tienen y cuáles son las tendencias para el futuro respecto a las redes sociales en el sector hotelero.

\section{MARCO TEÓRICO}

La literatura sobre el marketing en medios sociales en el sector hotelero suele tratar temas similares, estando relacionados entre sí. Concretamente, los estudios están referidos a la gestión, al uso y a la importancia de los medios sociales en el sector hotelero. Por lo tanto, en los siguientes apartados se tendrá en cuenta los estudios más relevantes divididos en tres puntos: la estrategia y la gestión de las redes sociales en el sector hotelero, el impacto de las redes sociales y a la prospectiva en el uso de las redes sociales en dicho sector.

\subsection{La estrategia y la gestión de las redes sociales en el sector hotelero}

Según Wichels (2016), los hoteles, las organizaciones de gestión de destinos y demás empresas turísticas, públicas o privadas, utilizan varios procesos y herramientas para comunicarse, formal e informalmente, con sus grupos de interés. El concepto de la comunicación turística no se reduce a la promoción de un hotel o destino, sino que engloba también los 
procesos de motivación de un turista y los intercambios culturales entre visitante y anfitrión, y las narrativas turísticas a través de las cuales se construyen las identidades de las gentes, lugares y marcas. Además, la comunicación turística está presente en las historias y fragmentos del viaje contados por el turista en el regreso a su lugar de destino y en las valoraciones que escribe en internet después del consumo.

De esta manera, las estrategias de comunicación se fundamentan en las capacidades del personal y de su sensación de bienestar dentro del ambiente de trabajo. La atención a los clientes y la promoción de los servicios que se ofrecen están condicionadas por la preparación de los empleados y la dinámica que se desarrolle dentro de los ambientes laborales. Por lo tanto, el uso de herramientas para agilizar la comunicación y hacerla más eficiente dependerá de la formación de los trabajadores y su disposición a las mejores formas de relacionarse (Zavala y Estrada, 2016; Aburrá, 2016).

La gestión de las redes sociales se ha considerado un aspecto crucial en la relación entre los servicios hoteleros y los consumidores. En este sentido, Martín y Arteaga (2016) mencionan que la importancia de este aspecto radica en hacer uso de las redes sociales más destacadas, así como considerar las vías mediante las cuales los clientes opinan sobre los servicios recibidos, con la finalidad de conservar o mejorar la reputación del hotel.

El gestor de las redes sociales o community manager es el encargado de vincular al cliente con el hotel, llevando a cabo las siguientes funciones (Cascales et al., 2015): buscar oportunidades para ampliar las fronteras de la comunidad; analizar tendencias en las demandas de los clientes y en el servicio hotelero; difundir contenido de alta calidad por distintos medios; hacer reportes de campañas e indagar sobre formas de entablar conversación con los clientes.

La importancia de las redes sociales y su gestión radica en su potencial para promover los servicios turísticos y relacionarse con las necesidades de los consumidores de una manera más directa. Piñeiro (2012) destaca algunas acciones a tener en cuenta en el uso de las redes sociales para cuidar la imagen empresarial y atender de manera más eficiente a los clientes. Estas acciones se definen en las siguientes características de las redes sociales:

- Aportan mayor valor a los servicios, ya que su oferta en redes sociales se convierte en una garantía de su existencia. Por lo tanto, los consumidores perciben mayor valor en la marca.

- Es posible centrarse en una comunidad. Aunque las redes sociales permiten llegar a todo tipo de usuarios, es recomendable enfocar la oferta de los servicios en una comunidad. Así, es más sencillo desarrollar contenidos de interés logrando un engagement por parte de los consumidores.

- Posibilitan el protagonismo por parte del consumidor. Al ser las redes sociales un canal de interacción, inciden en la sensación de satisfacción por parte de los clientes. De esta manera, es más fácil conocer sus expectativas y corresponder a ellas.

- Permiten ofrecer una respuesta rápida a las necesidades de los usuarios. A través de las redes sociales se contribuye a mejorar la experiencia de los clientes resolviendo sus dudas de manera inmediata o casi inmediata, lo cual favorece a la imagen de la empresa. 
- Por lo tanto, se cuida la reputación de la marca, fortaleciendo la confianza de los clientes hacia la empresa propiciando su recomendación.

En los estudios de Leung et al. (2017), Bueno et al. (2017) y Zavala y Estrada (2017) se sugieren a los establecimientos hoteleros las siguientes pautas de comportamiento en la gestión de las redes sociales:

- Crear contenidos de calidad que aporten valor a sus usuarios. También se recomienda la publicación de videos e imágenes que publiciten los servicios ofertados, y en este sentido anticipen a los turistas la experiencia y satisfacción que tendrán al momento de hospedarse.

- Concentrarse en una o dos redes sociales. Teniendo en cuenta a su público objetivo los hoteles deberían centrarse en aquellas redes donde está su target y no malgastar recursos teniendo presencia en todas ellas.

- Cuidar al usuario, el cliente debe ser el centro de atención. Éste debe sentirse escuchado y poder expresarse con libertad sin censurar sus comentarios. Los hoteles tienen que estar continuamente pendientes de los comentarios de los usuarios, de sus opiniones (buenas y malas), en definitiva, tienen que cuidar su reputación online y saber cómo y cuándo responder para evitar las temibles crisis de reputación online.

- Cuidar el tiempo de respuesta y sobre todo la forma en que se realiza esa respuesta. Si antes una respuesta a las 24-48 horas era comprensible, ahora estar en redes sociales implica inmediatez y el plazo de respuesta debe ser de horas y siempre inferior a 24 horas.

- Utilizar los concursos y promociones para conseguir interés en la comunidad y que esta comparta contenidos.

Los comentarios y opiniones de los usuarios en los medios sociales es un factor clave que deben gestionar los hoteles en los medios sociales. En el artículo de Ong (2012) se destaca que los usuarios cada vez le dan más importancia a las opiniones y reseñas que dejan otros usuarios en los medios sociales. Esto toma especial relevancia en el sector hotelero donde se producen gran cantidad de comentarios. Considera que los hoteles no están aún seguros de cómo tratar o responder a las críticas y comentarios de otros usuarios y esta incertidumbre es debida a la falta de comprensión acerca de cómo los consumidores perciben y utilizan los comentarios online.

\subsection{El impacto de las redes sociales en el marketing del sector hotelero}

La efectiva gestión de las redes sociales cobra cada vez más importancia por su impacto en el marketing del sector hotelero. En la actualidad, las redes sociales están abarcando casi la totalidad de las relaciones humanas y, por lo tanto, de las relaciones comerciales. Como menciona Destors (2010), una parte esencial del marketing es la investigación de mercados. Cuando se hace uso de internet, esto se dirige a escuchar lo que la gente opina.

La referencia a algunos estudios demuestra que las redes sociales tienen un fuerte impacto en la industria hotelera, lo cual se evidencia en los siguientes hechos (Four Pillars Hotels, 2015): 
- El 92\% de los clientes hace más caso a las recomendaciones de otros consumidores que dejan sus testimonios en las redes sociales que a cualquier otro medio.

- El 52\% de los usuarios han cambiado sus planes de viaje y reservas después de consultar las opiniones sobre un hotel.

- El $85 \%$ de los viajeros utilizan su móvil durante el tiempo que permanecen en un hotel.

- El $76 \%$ de los consumidores cuelgan fotos en las redes sociales durante sus viajes, lo cual incluye el hotel donde se alojan.

- Sólo el 46\% vuelve a dejar un comentario al volver al mismo hotel.

Por estas razones, la gestión de las redes sociales es un aspecto cada vez más relevante en el marketing del sector, ya que gran parte de las experiencias sobre la calidad, precio y tipo de servicios que se ofrecen se informan mediante internet. Por ello, resulta fundamental la organización de los contenidos en la página web de la empresa, así como su promoción en diferentes plataformas.

En síntesis, se destacan cuatro maneras en las que las redes sociales han transformado al sector turístico, y, por lo tanto, al hotelero (León, 2016):

1. Internet es la mejor guía de los turistas. De acuerdo con datos de TripAdvisor (2016), el $77 \%$ de los viajeros revisan los comentarios que han dejado los usuarios sobre los hoteles en los que se hospedaron.

2. El viajero es el mayor influenciador. Las redes sociales posibilitan que los consumidores obtengan información de primera mano e inmediata sobre la calidad y los precios de los hoteles.

3. Cada vez en más importante compartir las experiencias turísticas. El tema de los viajes en el más posteado en Facebook. Asimismo, el uso de hashtags y check-in son elementos que influyen en la perspectiva de los consumidores sobre los servicios hoteleros.

4. Las redes sociales son las mejores herramientas de marketing para el turismo debido a su alto número de usuarios y su uso para la planeación de sus viajes.

La reputación online es un tema de vital importancia en los medios sociales del sector hotelero, ya que, fruto de esta conversación, los hoteles serán conscientes de la importancia de gestionar su reputación online, y los efectos que las opiniones publicadas por los usuarios tienen sobre las ventas, y lo harán teniendo en cuenta los blogs, foros, redes sociales (tantos generales como las turísticas), así como cualquier punto de intercambio de información entre usuarios (Ortiz y González, 2014; López, 2010).

Respecto a la reputación online, en el estudio de Majó et al. (2018) se comprueba que una adecuada gestión de las redes sociales va asociada a una mejor reputación del hotel y esta a su vez con un mayor ingreso del hotel. Así, se considera esencial que existan responsables de las redes sociales encargados de gestionar las opiniones de los usuarios. En cualquier caso, todos los comentarios deben distribuirse a los departamentos afectados e incorporarse en la mejora permanente de la calidad. Se deben socializar entre todo el equipo buscando realizar cambios inteligentes para mejorar la experiencia de los huéspedes del hotel.

En el mismo sentido, García et al. (2017) consideran que es necesario que personal cualificado monitorice las acciones en las plataformas sociales, controlando la comunicación 
con los clientes, respondiendo a las posibles críticas o comentarios para mejorar la reputación online, y apostar por las plataformas sociales como nuevo canal de ventas. Así, demuestran que las redes sociales representan un nuevo canal de comunicación y venta y ayudan a mejorar la reputación de los establecimientos con un coste inferior a los canales tradicionales.

Por último, en el estudio de Diana-Jens y Ruibal (2015) consideran que los principales impactos de la reputación online, identificados desde la perspectiva del consumidor, se encuentran relacionados con aspectos relativos al proceso de decisión de compra, a la aceptación del producto, a la reducción del riesgo en la compra, a la percepción de credibilidad/ confianza, a la comparación entre diferentes hoteles, al conocimiento de marca, a la intención de compra y a la lealtad.

\subsection{Prospectiva del uso de las redes sociales en el sector hotelero}

Lo analizado hasta el momento demuestra que la gestión de las redes sociales se ha convertido en un reto cada vez mayor. La transformación de las TIC y su influencia en los consumidores es un aspecto que no se puede evitar debido a que en los últimos años se ha acrecentado. En este sentido, se destacan algunas tendencias de futuro sobre el uso de las redes sociales en el sector.

Las nuevas tecnologías y los dispositivos móviles van a convertirse en el centro del marketing. La rápida evolución de los móviles, smartphones, tablets y wearables apunta a una total digitalización del marketing a corto plazo (Yim et al., 2019). Linton y Kwortnik (2019) comentan que el auge de dispositivos móviles va a transformar las prácticas operativas y las experiencias de los clientes en la industria hotelera. Así, los hoteles usan las nuevas tecnologías y los dispositivos móviles para proporcionar servicios personalizados a los clientes y mejorar su lealtad. En este sentido, Lee (2018) especifica que la industria hotelera no solo se enfoca en identificar y retener clientes leales, sino que también mejora la rentabilidad de los clientes menos leales, siendo el marketing móvil un medio ideal para promover las relaciones entre clientes y proveedores de servicios, mejorando la gestión de las relaciones con los clientes.

El buen contenido no pasa de moda. La creación de contenidos interesantes es un aspecto que continuará siendo relevante en el marketing digital. Igualmente, las tendencias de contenido visual es un aspecto que estará cada vez más en auge y cobrará mayor importancia en el futuro, por lo que es un elemento a tener en cuenta. Así, el contenido de las redes sociales influye en la percepción del espectador sobre la imagen de un hotel en particular, lo que aumenta la popularidad (Ristova y Dimitrov, 2019).

El contenido generado por los usuarios será lo más usual. El gran alcance que tienen las redes sociales propiciará con mayor frecuencia que los viajeros compartan sus experiencias personales en sus propias páginas web o en sus redes personales, lo cual es un elemento a tener en cuenta en el vínculo que mantienen los hoteles con los consumidores (Tsiakali, 2018). Además, el contenido generado por el usuario todavía está en sus primeras etapas, y hay algunos aspectos que aún deben explorarse como el uso de las redes sociales como base de información de apoyo para la elección, organización y planificación de un viaje (Narangajavana Kaosiri et al., 2019). Esta importancia del contenido generado por el usuario se verá acrecentada por 
el impacto de los Millenials en el sector turístico. Los Millennials, son personas que nacieron entre 1980 y 2000 y contribuyen, comparten, buscan y consumen activamente contenido en plataformas de redes sociales. Los Millennials son quizás los grupos demográficos más populares en la industria turística y hotelera actual, pero también pueden ser los más difíciles de atraer, convirtiéndose esto en un reto de las empresas turísticas. Quieren experiencias individualizadas mientras viajan, donde pueden expresar su personalidad, pero también requieren accesibilidad y flexibilidad en la reserva (Espigares-Jurado et al., 2020). Parte del hecho de que ha sido difícil atraer a los Millennials es que a menudo evitan los canales de comunicación convencionales (anuncios impresos, radio y televisión) porque los Millennials consideran que las redes sociales son cruciales para su vida profesional y personal (Breda et al., 2019). Es importante destacar que los Millennials no deben verse solo como turistas e invitados que usan las redes sociales como una forma de compartir fotos de su vida cotidiana. En un mundo digital altamente conectado, muchos Millennials realmente trabajan y contribuyen a esta industria, lo que los convierte en un mercado altamente demandado (Santos-Corrada et al., 2019).

Se prevé para el futuro un mayor crecimiento y utilización de la red social de Instagram en el sector turístico. Según el estudio de IAB Spain (2019), Instagram es la red social de más rápido crecimiento en todo el mundo, con mil millones de usuarios activos. Oliveira (2014), especifica que Instagram es una red social dirigida para su uso en móviles inteligentes. En los estudios de I Agustí (2018) y Camara (2019) consideran que muchas compañías van a elegir a Instagram como un medio para promocionar sus productos/servicios, ya que permite una mayor interacción y visibilidad, además de ofrecer un costo más bajo. Además, en el segmento turístico, marcado por el carácter de los servicios, el consumo de los destinos está influenciado por Instagram a través de la mayor visibilidad y alcance que puede obtener el contenido insertado en este medio.

La utilización del video como plataforma publicitaria también está cobrando gran importancia en el ámbito turístico. Por ejemplo, solo en YouTube, los usuarios miran más de mil millones de horas de material de video todos los días. Las estadísticas muestran un rápido aumento en la cantidad de material de video que se consume en línea en todo el mundo (Alamäki et al., 2019). Además, este consumo se está haciendo cada vez más en dispositivos móviles, que se han convertido en terminales finales importantes para el consumo de contenido en línea (Chen et al., 2017).

A través de redes sociales los clientes comparten cada vez más sus experiencias online y es importante que los hoteleros lo tengan en cuenta. Para ello se utilizará cada vez más en la gestión los software o herramientas. En el mismo sentido, las mediciones sobre el éxito de las estrategias de marketing serán más precisas. Así, se perfeccionarán las herramientas analíticas para mejorar las campañas y medir el éxito de los productos. Las novedades que se producen en las redes sociales cada vez son más habituales y se producen con mayor frecuencia, por lo tanto, los gestores tendrán que tener cada vez más en cuenta esta evolución (Muñoz-Leiva et al., 2019; Mirzaalian y Halpenny, 2019). Además, según Martins et al. (2018) las redes sociales permiten herramientas orientadas a los negocios, de las cuales se destacan las siguientes: perfiles de negocios, que permite que el cliente se ponga en contacto y vea la dirección de la empresa; promoción, que permite publicar en forma de publicidad; y las estadísticas, una 
herramienta para medir los resultados de la compañía con respecto a su participación en la red. En las estadísticas se mostrarán métricas como las mejores publicaciones, el alcance, las impresiones y el compromiso, así como más datos sobre los seguidores, como el sexo, la edad y la ubicación, incluida la ciudad específica. También mostrará el momento en que tus seguidores usan más dichas redes sociales.

Las redes sociales se están convirtiendo en un nuevo motor de búsqueda, Muchos consumidores prescinden de buscadores más tradicionales de páginas web y en su lugar prefieren buscar información en sus redes de social media (Carpio Maraza et al., 2019). Por ello los hoteleros deberían asegurarse de incluir contenido relevante en sus publicaciones para que los usuarios puedan encontrar el establecimiento en sus redes.

\section{METOdOLOGÍA}

\subsection{Diseño de la investigación}

El planteamiento metodológico tiene un enfoque cualitativo basado en un análisis de contenido sobre las entrevistas realizadas a los gestores de las redes sociales en el sector hotelero. Un estudio adquiere el enfoque cualitativo cuando se quiere comprender y profundizar los fenómenos, explorándolos desde la perspectiva de los participantes en un ambiente natural y en relación con el contexto" (Hernández et al., 2010). Así, la investigación cualitativa posibilita la comprensión de una realidad concreta a través del análisis de las perspectivas de los representantes de una realidad, en este caso, los gestores de las redes sociales del sector hotelero.

En la investigación cualitativa es el propio investigador quien recoge los datos a través de diversas técnicas como pueden ser las observaciones, las entrevistas, la revisión documental o la conducción de sesiones con los participantes (Hernández et al., 2010). Para los propósitos de esta investigación se ha decidido el uso de la entrevista ya que va a permitir conocer y obtener las percepciones de los gestores sobre el uso de las redes sociales en el sector hotelero.

En relación con el método de investigación se siguen las etapas del proceso de análisis de contenido propuesto por Sociales y Chaves (2002) y Rodríguez et al. (1999):

1. Se selecciona la muestra o los participantes formado por los gestores de redes sociales del sector hotelero.

2. A través de un enfoque deductivo se definen las categorías teniendo en cuenta el marco teórico establecido, a partir de las cuales se establecen las preguntas de la entrevista.

3. Se recopilan los datos y se determinan las unidades de análisis dentro de la información recopilada (codificación de datos).

4. Mediante un enfoque inductivo con el uso del software Nvivo 11 se obtienen subcategorías dentro de las categorías anteriores a través de la identificación en los datos de nuevos temas con características comunes.

5. Se determinan las unidades de análisis para las subcategorías y se codifican los datos. 
6. Se obtienen los resultados de la investigación, los cuales se establecen a partir de la interpretación de la información.

\subsection{Muestreo y recopilación de datos}

Para la selección de los participantes en la investigación cualitativa se llevó a cabo un muestreo deliberado e intencional (Woolthuis et al., 2005), de esta manera las fuentes de información se eligieron en función del grado con el que cada uno se ajusta a los criterios determinados por el investigador. Teniendo en cuenta los objetivos de la investigación se ha decido que los participantes sean los encargados de gestionar las redes sociales o community managers de empresas hoteleras que lleven a cabo una participación activa en los medios sociales.

De esta manera, para esta investigación se han seleccionado 10 gestores de redes sociales de los siguientes hoteles y cadenas de hoteles de la provincia de Cádiz:

1. Hotel Las Cortes.

2. Hotel Guadalquivir.

3. Hotel Monterrey Costa de Chipiona.

4. Hotel San Roque Suites.

5. Hotel La Catedral.

6. Hotel Royal Hideaway Barceló Sancti Petri.

7. Cadena de hoteles HACE.

8. Cadena de hoteles Meliá.

9. Cadena de hoteles RIU.

10. Cadena de hoteles NH.

Para la recopilación de la información se ha utilizado la entrevista. Este método tiene como principales funciones obtener información, influir en determinados aspectos de la conducta o ejercer algún efecto terapéutico (Rodríguez et al., 1999). La definición de las preguntas a realizar está condicionada por el tipo de entrevista que se realice. Siguiendo el análisis de Vargas (2012) las entrevistas pueden ser estructuradas, no estructuradas o semiestructuradas. Para efectos de la presente investigación se ha utilizado la entrevista semiestructurada con el propósito de obtener información relevante que contribuya a responder las preguntas de investigación. En la entrevista semiestructurada las preguntas están definidas previamente en un guion, pero la secuencia, así como su formulación pueden variar en función de cada sujeto entrevistado. Es decir, el investigador realiza una serie de preguntas (generalmente abiertas al principio de la entrevista) que definen el área a investigar, pero tiene libertad para profundizar en alguna idea que pueda ser relevante, realizando nuevas preguntas. Las entrevistas fueron realizadas entre los meses de enero-marzo del 2019, siendo de manera personal y grabadas para su posterior transcripción a texto, facilitando así el análisis de la información.

Previamente se han identificado las categorías de análisis que indican las expectativas sobre cómo debe ser tratado el tema. En este sentido, las categorías establecen una norma sobre cómo trabajar los datos obtenidos mediante las técnicas de recopilación de información (Martín, 1995). Estas categorías se han definido a partir del marco teórico, el cual se ha 
fundamentado en la revisión y en el análisis de las investigaciones y documentos especializados en el sector hotelero.

Teniendo en cuenta estas categorías se especifican las preguntas de investigación realizadas a los gestores de las redes sociales de la muestra y que dan respuesta a los objetivos planteados (tabla 1).

Tabla 1. Definición de categorías de análisis y preguntas de investigación

\begin{tabular}{|c|c|c|}
\hline Categorías de análisis & Preguntas de investigación & Referencias \\
\hline $\begin{array}{c}\text { Los objetivos y las es- } \\
\text { trategias en las redes } \\
\text { sociales }\end{array}$ & $\begin{array}{c}\text { ¿Cuáles son los principales objetivos } \\
\text { que plantea con el uso de las redes } \\
\text { sociales en el hotel? } \\
\text { ¿Qué estrategias utiliza para alcanzar } \\
\text { dichos objetivos? }\end{array}$ & $\begin{array}{c}\text { Wichels, (2016); Zavala y Estrada } \\
\text { (2016); Aburrá (2016) }\end{array}$ \\
\hline $\begin{array}{c}\text { La gestión de las redes } \\
\text { sociales }\end{array}$ & $\begin{array}{c}\text { ¿Qué gestión lleva a cabo sobre las } \\
\text { redes sociales? ¿Cómo la gestiona? }\end{array}$ & $\begin{array}{c}\text { Martín y Arteaga (2016); Cascales } \\
\text { et al. (2015); Ong (2012) }\end{array}$ \\
\hline $\begin{array}{c}\text { El impacto de las redes } \\
\text { sociales }\end{array}$ & $\begin{array}{c}\text { ¿Cuál considera que es el impacto y } \\
\text { la relevancia que generan las redes } \\
\text { sociales en el sector hotelero? }\end{array}$ & $\begin{array}{c}\text { Destors (2010); León (2016); Majó } \\
\text { et al. (2018); García et al. (2017); } \\
\text { Diana-Jens y Ruibal (2015) }\end{array}$ \\
\hline $\begin{array}{c}\text { Prospectiva de las re- } \\
\text { des sociales }\end{array}$ & $\begin{array}{c}\text { ¿Cuál considera que será la } \\
\text { tendencia del uso de las redes } \\
\text { sociales en el sector hotelero? }\end{array}$ & $\begin{array}{c}\text { Linton y Kwortnik (2019); (Ristova } \\
\text { y Dimitrov (2019); Tsiakali (2018); } \\
\text { I Agustí (2018); Alamäki et al. } \\
\text { (2019); Muñoz-Leiva et al. (2019) }\end{array}$ \\
\hline
\end{tabular}

Elaboración propia.

\subsection{Proceso de codificación y análisis de datos}

Una vez realizadas las entrevistas se llevó a cabo la transcripción literal de la información obtenida en las mismas. Posteriormente, siguiendo el planteamiento metodológico, se procedió a codificar los datos. El proceso de codificación consiste en la identificación de unidades de análisis que les dan sentido a las categorías empíricas y constituyen las reflexiones que se realizan a partir de los datos obtenidos.

Una vez recopilados los datos en unidades de análisis se obtienen subcategorías dentro de las categorías anteriores. En este caso se realiza una categorización inductiva, ya que las subcategorías se obtienen una vez se ha recogido la información, a través de los datos con base al examen de los patrones y recurrencias presente en ellos (Chaves, 2005). La categorización inductiva en las entrevistas ha sido tratada en diversos estudios como los de Hai-Jew, 2014; Hemar-Nicola et al., 2013 y Rhodes et al., 2014.

Los datos se analizaron mediante un análisis de contenido. El análisis de contenido es un enfoque de análisis utilizado para identificar la presencia de conceptos y temas dentro de un conjunto de datos cualitativos. El análisis de contenido cualitativo va más allá de identificar el texto objetivo, en un intento de buscar significados y determinar temas extraídos de la información para obtener una mayor comprensión de las realidades sociales (Ellingson, 2013; Lehtonen, 2000; Rickly-Boyd, 2013). Los investigadores se preocupan por el contexto de las 
narrativas y las experiencias comunicadas y categorizan los temas emergentes integrados en el contenido (Banyai y Glover, 2012). Así, la investigación de contenido cualitativo se ocupa de producir descripciones y tipologías relativas a expresiones que destacan cómo las personas perciben el mundo social y empresarial. Por lo tanto, este enfoque es una forma efectiva de analizar los datos obtenidos de las entrevistas permitiendo la comprensión del uso de las redes sociales en el sector hotelero.

Para categorizar y codificar los datos del contenido generado por el usuario incluidos en esta investigación la información fue exportada al software Nvivo 11 ya que de esta manera se reduce significativamente las implicaciones de tiempo y la complejidad asociada con la categorización manual. Utilizando el software Nvivo 11 fue posible identificar temas con características comunes permitiendo la clara identificación de diferentes subcategorías en las que se va a organizar la información y el desarrollo de marcos de codificación. En la tabla 2 se especifican las subcategorías obtenidas en el análisis de la información junto con su descripción.

Tabla 2. Categorías y subcategorías

\begin{tabular}{|c|c|}
\hline Categorías de análisis & Subcategorías de análisis \\
\hline $\begin{array}{l}\text { Los objetivos y las estrategias en } \\
\text { las redes sociales }\end{array}$ & $\begin{array}{l}\text { Objetivos de comunicación: define los objetivos que se platean } \\
\text { en las redes sociales. } \\
\text { Estrategias de comunicación: define las estrategias que se utili- } \\
\text { zan para el logro de los objetivos que se plantean. }\end{array}$ \\
\hline La gestión de las redes sociales & $\begin{array}{c}\text { Actividades del gestor: indica las principales actividades que se } \\
\text { realizan los gestores de las redes sociales. } \\
\text { Tipos de redes sociales: establece en qué redes sociales está } \\
\text { presente el hotel y cuáles son las más importantes. } \\
\text { Factores de éxito de la comunicación en las redes sociales: se } \\
\text { refiere a los elementos clave que han producido un uso efectivo } \\
\text { de las redes sociales en el sector hotelero. } \\
\text { Herramientas de gestión: indica que tipos de herramientas de } \\
\text { gestión se usan en las redes sociales de los hoteles y cuales son } \\
\text { más útiles }\end{array}$ \\
\hline El impacto de las redes sociales & $\begin{array}{l}\text { Importancia de las redes sociales: establece la importancia del } \\
\text { uso de las redes sociales en el sector hotelero. } \\
\text { Importancia de las redes sociales respecto al resto de estrate- } \\
\text { gias de comunicación: indica la importancia de las redes sociales } \\
\text { respecto al resto de estrategias de comunicación. } \\
\text { Utilidad o Impacto de las redes sociales en el sector hotelero: } \\
\text { grado en que las redes sociales han beneficiado la comercializa- } \\
\text { ción de los servicios hoteleros. } \\
\text { Valoración de las redes sociales: reconocimiento de las ventajas } \\
\text { y desventajas del uso de las redes sociales en el sector hotelero. }\end{array}$ \\
\hline Prospectiva de las redes sociales & $\begin{array}{l}\text { Prospectiva de las redes sociales: tendencias en el uso de las } \\
\text { redes sociales en el sector. }\end{array}$ \\
\hline
\end{tabular}

Elaboración propia. 
Finalmente, una vez se especifican las unidades de análisis de las subcategorías mediante la codificación de los datos, se interpreta dicha información de las unidades de análisis para obtener los resultados de la investigación.

\section{RESULTADOS}

A continuación, se describen los resultados del estudio. En primer lugar, se va a mostrar la representación mediante un mapa jerárquico de la obtención de las subcategorías identificadas mediante el software Nvivo 11. Posteriormente se muestran los resultados mediante el análisis de la información recopilada en las subcategorías identificadas previamente, comenzando con los resultados sociodemográficos obtenidos en las entrevistas y, posteriormente, analizando las distintas categorías.

\subsection{Mapa jerárquico}

Tal como se ha especificado en la metodología en primer lugar se ha llevado a cabo la identificación de temas con características comunes permitiendo la clara identificación de diferentes subcategorías en las que se va a organizar la información.

De esta forma se ha obtenido la estructura jerárquica, donde los diferentes temas son agrupados dentro de cada categoría principal. El mapa jerárquico es una herramienta de análisis que proporciona el software NVIVO 11 que permite conocer de manera gráfica, de una parte, la estructura jerárquica de los diferentes códigos o nodos utilizados para el análisis, proporcionada por la propia estructura que se observa en el mapa, y, de otra parte, cuál es la frecuencia de aparición en el texto de cada uno de ellos, medido por el volumen de cada una de las cuadrículas representadas.

De esta manera, en las figuras 1, 2, 3 y 4 se representa el mapa jerárquico para cada categoría. Los colores muestran la jerarquía, mientras más alto sea el nivel más oscuro es el color. En este caso se muestran tres niveles: categorías, subcategorías y temas dentro de cada subcategoría. 
Figura 1. Mapa jerárquico de la categoría objetivos y estrategias de las redes sociales

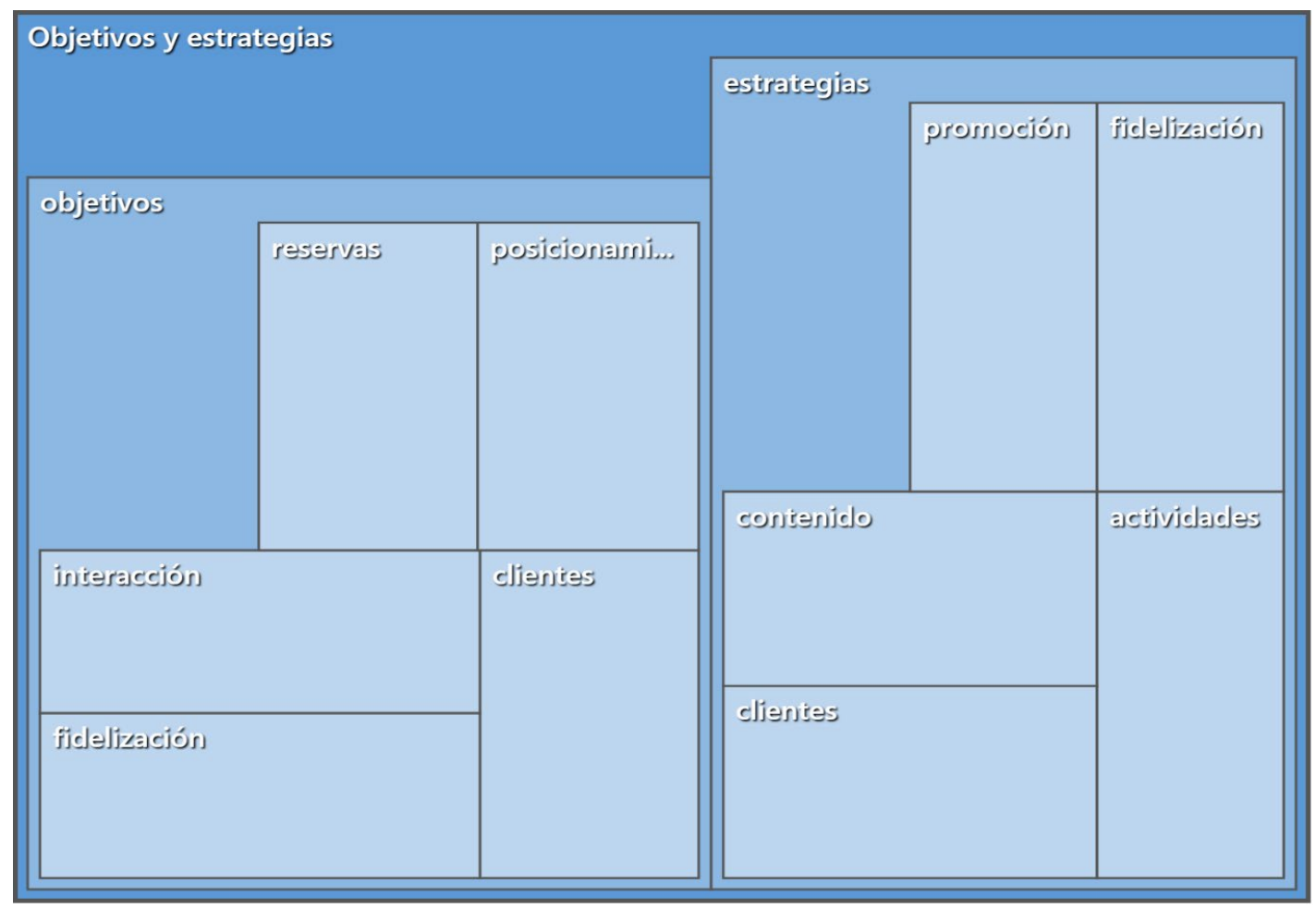

Elaboración propia.

Figura 2. Mapa jerárquico de la categoría gestión de las redes sociales

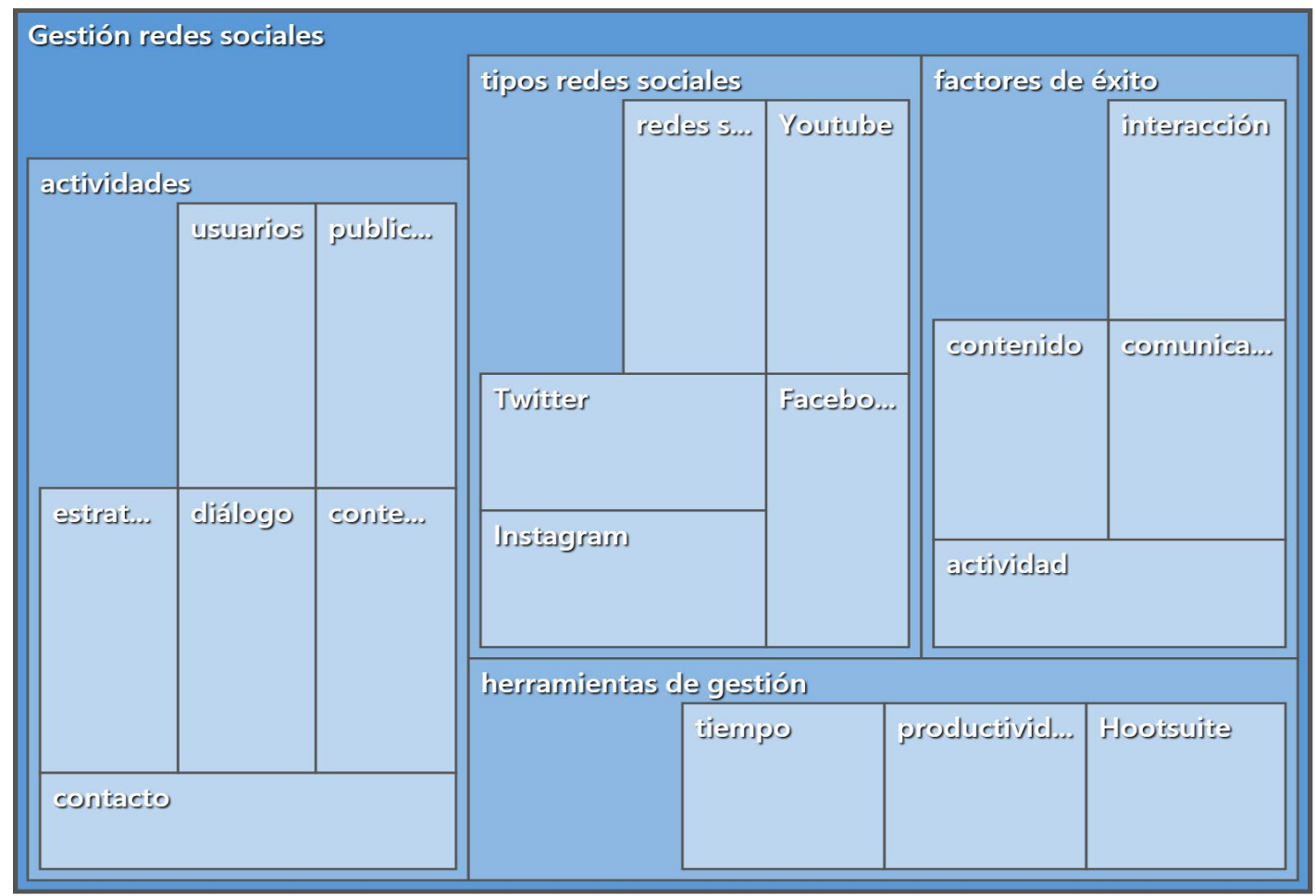

Elaboración propia. 
Figura 3. Mapa jerárquico de la categoría impacto de las redes sociales

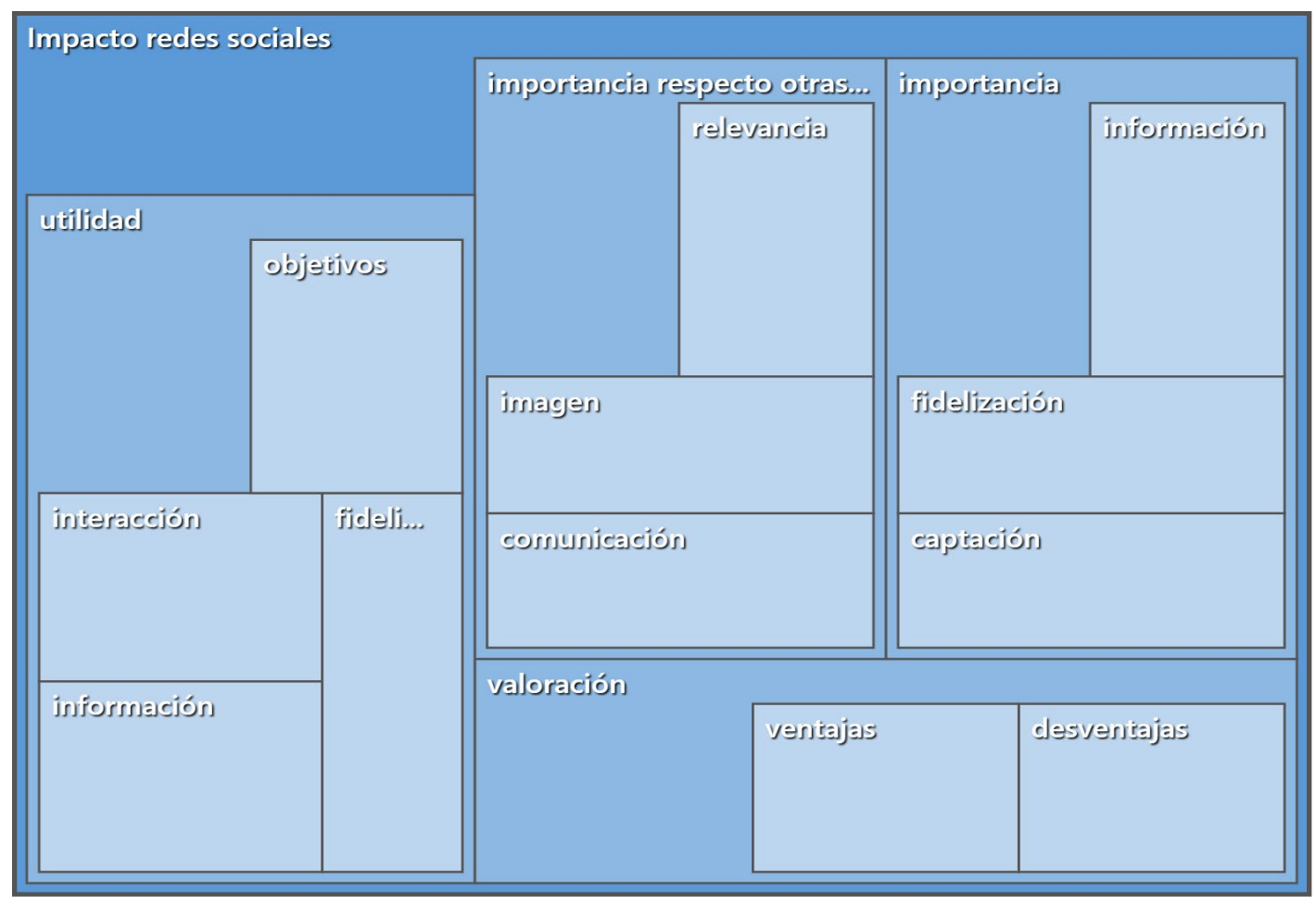

Elaboración propia.

Figura 4. Mapa jerárquico de la categoría prospectiva de las redes sociales

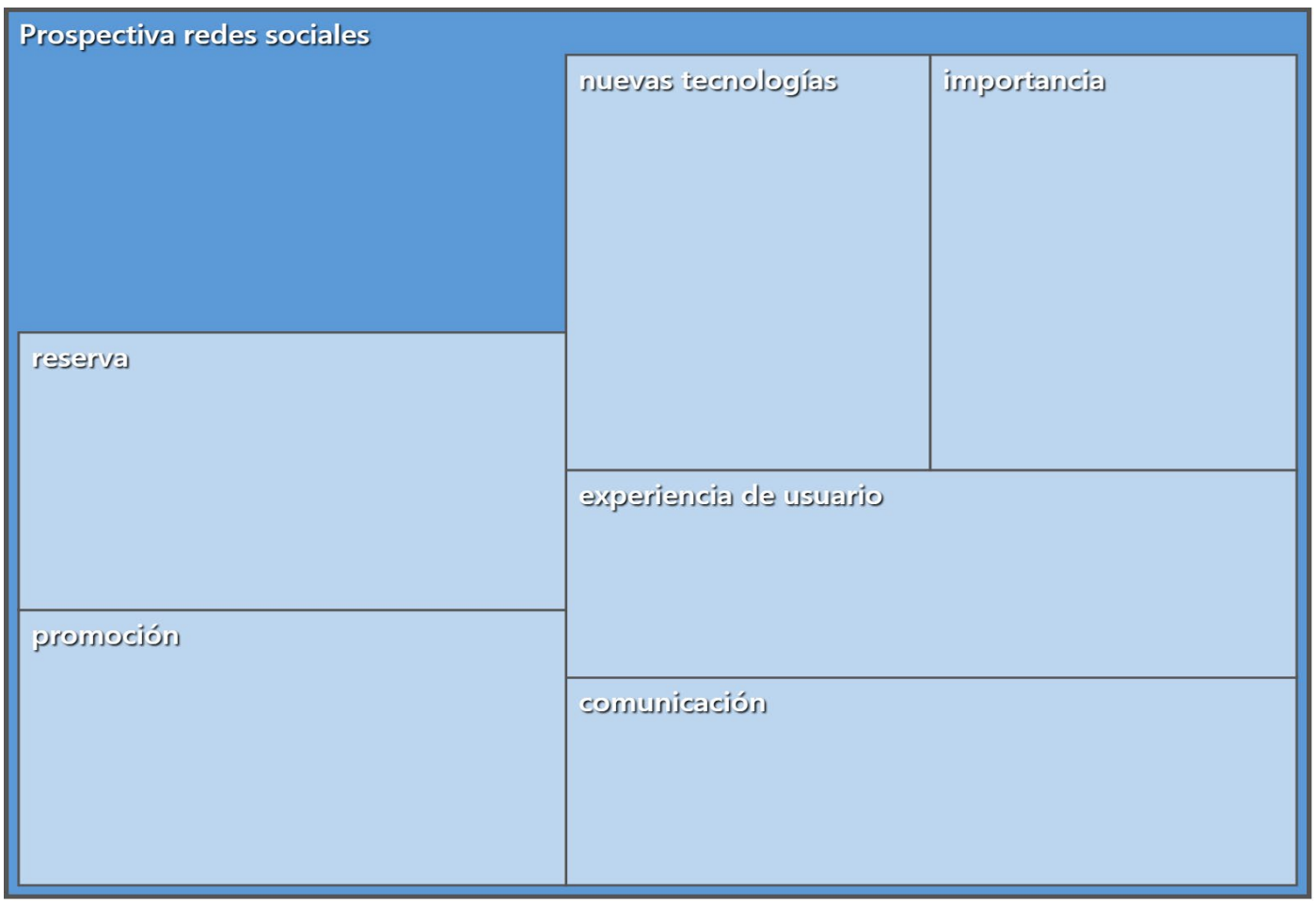

Elaboración propia. 


\subsection{Información sociodemográfica}

Teniendo en cuenta la edad de la muestra seleccionada, ocho de los diez entrevistados tienen menos de 30 años. Del resto, uno tiene 37 años y el otro 44.

Más significativos son los estudios realizados por los partícipes en la investigación que están, por lo general, relacionados con las redes de comunicación: tres graduados en marketing, dos en periodismo, dos licenciados en empresariales, uno en publicidad y relaciones públicas, uno en ingeniería informática y uno en filología inglesa. Todos son licenciados, por lo que el nivel de estudios puede considerarse alto.

Todos son los responsables del entorno digital en el hotel o cadena hotelera y ocupan puestos de ejecutivos medios. Cinco son community managers, cuatro social media managers y uno director comercial.

La última información extraída de los datos sociodemográficas se refiere al tiempo que los diez entrevistados llevan desempeñado su labor en el puesto de trabajo. En este caso hay bastante disparidad, dos de ellos permanecen más de 8 años, seis llevan de 2 a 5 años y, por último, dos de ellos llevan menos de 4 meses en el puesto.

En líneas generales cabe destacar la escasa edad de los entrevistados y la disparidad en el tiempo que llevan desempeñando su labor.

\subsection{Objetivos de comunicación}

Los entrevistados consideran, en general, que el principal objetivo en las redes sociales es incrementar el número de reservas del hotel, y, por lo tanto, conseguir que los usuarios se interesen por los servicios hoteleros a través de la difusión del conocimiento sobre la empresa en las redes sociales. De esta manera, se intenta visibilizar la marca y trabajar para que los usuarios continúen consumiendo sus servicios. En este sentido, se tiene el propósito de lograr que los usuarios sean promotores de la empresa para generar más clientes. Así, los objetivos de las redes sociales se centran en la comercialización de los servicios y el posicionamiento de la marca en internet. De esta forma, tienen la finalidad de interactuar con los clientes y mejorar su experiencia turística con la intención de atraerlos y fidelizarlos.

Uno de los objetivos más destacados por los entrevistados consiste en mantener la presencia del hotel en la red y posicionarlo en uno de los primeros lugares en los motores de búsqueda. Es importante que el hotel esté visible, tanto para los clientes actuales como los potenciales. Así, se considera que la misión de los community manager es, esencialmente, dar a conocer el hotel y sus servicios, sus promociones y las ventajas que ofrece en cada época del año.

\subsection{Estrategias de comunicación}

Las estrategias más usuales especificadas por los entrevistados radican en dar respuesta inmediata a las opiniones y preguntas planteadas por los clientes en las redes sociales, mostrar diariamente las ofertas del hotel y sus novedades, organizar eventos con los que dan a conocer 
el hotel y los servicios, así como la creación de contenido para que se visualice la riqueza del lugar y sea interesante para el público. También se utiliza el mailing para la promoción de los hoteles y el uso de vídeos, fotos o concursos que puedan interesar a los clientes potenciales. En algunos casos, también se tiene comunicación con influencers o líderes de opinión con la finalidad de que promuevan la marca.

Las redes sociales van a permitir varias estrategias: dirigirse a segmentos de la población y al tiempo incidir en un amplísimo entorno, realizar lanzamientos estacionales, ofrecer promociones en función de los días de la semana, etc. En definitiva, pueden establecerse estrategias de captación de clientes y fidelización de manera permanente y dirigida.

Cabe destacar que la estrategia depende también del objetivo que pretenda alcanzar el hotel, si prefiere ofrecer sol y playa, actividades, calidad, gastronomía, etc., es decir, cada hotel quiere explotar un target y la estrategia que se emplee está, pues, en función del mismo.

\subsection{Actividades del gestor}

Un resumen de las actividades que, como responsables de la gestión de la red social, realizan los entrevistados son:

- Coordinar las redes sociales.

- Establecer las estrategias de actuación en internet.

- Desarrollar dicha estrategia.

- Revisar diariamente en la red de las novedades que puedan afectar al hotel.

- Elaborar el contenido de los mensajes en las redes sociales.

- Gestionar las bases de datos para un mejor tratamiento de la información lo que permitirá llegar a clientes actuales y potenciales.

- Establecer y promover el diálogo, así como atender a las quejas y las dudas de los clientes.

- Analizar y reportar los resultados.

- Enviar e-mails para que los usuarios estén en contacto con el hotel e informados de las actividades del mismo.

- Renovar los contenidos periódicamente.

En realidad, para la mayoría de los entrevistados, la principal labor del community manager es mantener activos los canales de redes sociales y la atención de los usuarios. Esta labor se basa en la creación de contenido y la resolución de preguntas. También consideran que los usuarios cada vez más prefieren comunicarse a través de la red en lugar de usar otros medios como el teléfono o consultar en la propia recepción.

Además de las tareas que ya se han mencionado, la mayor parte de los entrevistados realizan otro tipo de labores que no son tan comunes y dependen del puesto de trabajo o las actividades asumidas por él. En algunos casos se han unificado las labores de publicidad a través de la red con la publicidad directa por medio de mailing, buzoneo, etc. 
Además, el intercambio de información y las preguntas y respuestas entre el hotel y los usuarios implica una gran cantidad de información que permite conocer la opinión que los usuarios tienen del hotel, pudiendo actuar así en consecuencia.

\subsection{Tipos de redes sociales}

Las redes sociales seleccionadas por todos los entrevistados para estar presente son en este orden:

- Facebook.

- Twitter.

- Instagram.

- Linkedln.

- Google+.

- Youtube.

Aun cuando prácticamente todos están de acuerdo en que Facebook es la más amplia e importante de las redes, hay diferencias respecto al interés que cada empresa hotelera puede tener por una u otra. Algunos enfatizaron que el tipo de red social en la que se interviene está relacionado con la finalidad que se pretende alcanzar.

Así, Facebook permite una mayor interacción y la posibilidad de llegar a más personas, Instagram posibilita promover la marca mediante imágenes y vídeos. Por su parte, Twitter es una red que se enfoca a dar visibilidad e información concreta sobre la marca, aunque la temporalidad de dicha información es más corta que en Facebook. En el caso de las grandes cadenas hoteleras, se utilizan otras redes como Weiboo, Wechat y Snapchat, que permiten llegar a regiones con gran cantidad de clientes potenciales como es Asia.

A través de Facebook y Twitter es posible llegar a un mayor número de usuarios, por lo que son totalmente necesarias para la promoción de la empresa hotelera.

Linkedln resulta más adecuado para un posicionamiento respecto a las agencias de viaje, pero no deja de ser una cuarta o, en ciertas ocasiones, quinta red social más usada.

Instagram presenta una serie de ventajas, se trata de una red social en el que el mensaje se transmite, esencialmente, por medio de imágenes o videos, lo que permite mostrar las habitaciones e instalaciones del hotel y en consecuencia la calidad del hotel, pero es una red con mucho menor público potencial que Facebook o Twitter. Consideran que es importante estar en ella, siempre que se mantenga la presencia en las dos primeras.

Youtube es una red con un tratamiento especial. Basa su funcionamiento en la subida de videos y si bien, como se ha especificado anteriormente para Instagram, esto permite mostrar las dependencias del hotel, es difícil de conseguir un buen posicionamiento en ella.

También existen una serie de redes, no genéricas, especializadas en la industria hotelera y viajes, como Booking, Trivago o TripAdvisor. Algunos entrevistados las utilizan para conocer la opinión de los usuarios respecto al hotel. 
También es evidente que, para hoteles pequeños y muy especializados la red social más adecuada es Facebook. Mientras que las cadenas hoteleras, al ser más grandes y diversificadas, intervienen en más medios sociales.

En general, para las empresas hoteleras lo importante es estar visibles en todas las redes, con mayor incidencia en Facebook y Twitter.

\subsection{Factores de éxito de la comunicación en las redes sociales}

La respuesta a esta categoría ha proporcionado un amplio espectro de factores considerados relevantes. A continuación, se especifica el listado de los principales:

- Mantenimiento activo en las redes y el feedback con los clientes como aspectos clave.

- Establecer una correcta comunicación, especialmente en la interacción entre el hotel y usuarios. Dos de los participantes en la encuesta consideran como relevante crear un lenguaje (lo denomina tono) propio del hotel y mantener la comunicación dentro de dicho lenguaje. Esto crea una dinámica intimista entre el hotel y el cliente que favorece la fidelización. De esta manera, suele presentarse un mensaje más familiar o social en lugar de una presentación más formal o institucional.

- Promocionar y defender la imagen de la empresa hotelera, así como justificar las críticas negativas que suelen producirse por parte de los usuarios.

- Informar al usuario no sólo sobre la marca o el propio hotel sino sobre el entorno en el que se ubica. Comunicar todo lo que concierne al hotel y las actividades que pueden encontrarse y realizarse en el mismo y en su entorno, mejorando así la experiencia del usuario.

- Las estrategias que se planteen deben estar muy relacionadas con la naturaleza de cada una de las redes y del público objetivo al que se dirija el hotel. Es decir, la estrategia del hotel debe adaptarse a las características de cada red y hasta de cada individuo que interactúe en ella, si esto es posible. Para ello es preciso, según algunos entrevistados, ser proactivo, lo que implica, además de estar presente, crear y actualizar contenidos en las redes constantemente.

\subsection{Herramientas de gestión}

La plataforma más utilizada y recomendada por la mayoría de los entrevistados es Hootsuite, especialmente su versión Enterprise, la cual es considerada como una herramienta que permite manejar diferentes redes sociales mejorando el tiempo y la productividad. Varios entrevistados hacen mención al coste extra que conllevaría el uso de herramientas de gestión, de esta manera dos de ellos utilizan Postcron por ser más económica.

Dos de los entrevistados destaca la herramienta Review Pro, siendo considerada como una plataforma dedicada a conectar las redes sociales y páginas de relevancia en la red, como Googing o Expedia que son una excelente fuente de reservas.

También hay cierto consenso en que el interfaz de Facebook es muy práctico y aporta lo necesario para gestionar un perfil, y además posee una serie de herramientas de análisis 
muy interesantes. Aunque también destacan que cada vez las propias plataformas de las redes sociales ofrecen facilidades para los servicios de gestión y análisis.

Aquellos que no utilizan herramientas de gestión han confesado que estarían dispuestos a usarlas en el futuro. Por lo que, en general, hay un cierto consenso en que es importante disponer de un buen servicio de herramientas accesorias que estén integradas y permitan una mejor y más ágil gestión en las redes sociales.

\subsection{Importancia de las redes sociales}

La cuestión sobre la importancia de las redes sociales es positiva y unánime en todos los entrevistados. En dos casos con matices poco significativos. La opinión es que el uso de las redes en el sector hotelero no es solo importante sino esencial para la captación de clientes $y$, consecuentemente, para el buen fin del negocio. Cierto que algunos lo asocian más con el ámbito turístico, es decir, entienden que el objetivo del hotel no es tanto sus prestaciones sino el servicio como destino turístico.

Entre los principales elementos que caracterizan dicha importancia se encuentra en que las redes sociales son usadas por millones de personas en todo el mundo. Además, son herramientas útiles para contactar con personas que están físicamente lejos, sirviendo de punto de partida para que los usuarios conozcan las instalaciones y los servicios.

Respecto a que las redes sociales sean las herramientas más idóneas y más usadas para conseguir ventas no todos están de acuerdo, pero sí lo están en que es una vía esencial para dar a conocer la oferta hotelera. Los clientes tienen además la posibilidad de interactuar con el hotel y con otros clientes e intercambiar opiniones sobre la calidad de los servicios o informarse de los mismos a través de comentarios y opiniones de otros que han pernoctado en dicho hotel.

Los gestores coinciden en que, cada vez más, los usuarios tienden a informarse por medio de internet y las redes sociales cuando quiere encontrar un hotel o quieren conocer sus características.

En resumen, según los entrevistados, las redes sociales son la forma más eficiente para dar a conocer la marca, fidelizar a los usuarios y expandir la información sobre la calidad de los servicios que se ofrecen. Igualmente, permiten analizar quienes hablan sobre la marca y cuáles son las impresiones sobre ésta.

\subsection{Importancia de las redes sociales respecto al resto de estrategias de comunicación}

Todos consideraron que cada vez tienen más relevancia las redes sociales en comparación con las estrategias tradicionales de la comunicación. Su diversificación permite cumplir diferentes objetivos y dirigirse a distintos públicos, así como crear una comunicación directa y sencilla.

De acuerdo con los entrevistados, las redes sociales son menos invasivas que otras formas de interacción con los clientes, brindando la posibilidad de medir la cantidad de 
personas que ven las publicaciones y valorar quienes están interesados en el hotel. Por otra parte, representan la imagen de la empresa y condicionan las reservas, puesto que la mayoría de las personas consultan las redes antes de decidir su estancia en un determinado hotel.

Uno de los entrevistados especifica que la estrategia digital está integrada en todas las áreas de la compañía, es decir, pertenece al plano de la responsabilidad social corporativa, de la marca y de los RR.HH. Esto lo corrobora otro gestor, cuando afirma que la empresa necesita estar integrada en las redes sociales de manera que desde los demás departamentos contribuyan a la imagen del hotel o de la cadena hotelera en internet.

\subsection{Utilidad o Impacto de las redes sociales en el sector hotelero}

La respuesta general sobre la incidencia de las redes sociales en el sector hotelero ha sido muy positiva. Consideran que es inevitable estar presentes en las redes sociales debido a su popularidad entre los usuarios, ayudando a reforzar el número de reservas y el logro de los objetivos. Además de visibilidad, las redes sociales difunden la calidad de los servicios hoteleros.

En general, consideran que el sector hotelero ha asumido la revolución tecnológica y la sociedad global de la información y la comunicación de manera plena y, hoy día, hay pocas empresas que se muestren reacios a utilizar dichas las TICs en toda su capacidad para lograr los objetivos propuestos.

Varios entrevistados consideran que las redes sociales han servido, principalmente, para fidelizar a los clientes, siempre que la utilización de las herramientas esté bien planteada y se logre explicar claramente el mensaje que se quiere transmitir.

También surge el problema que plantea la gestión de los elementos de interacción con los clientes. Concuerdan los entrevistados que es importante cuidar estos instrumentos de manera diaria, es decir, comprobando y respondiendo los comentarios que los usuarios han enviado, las preguntas que realizan, las cuestiones sobre las que demandan información, etc.

Algunos de los entrevistados destacan nuevos factores, como, por ejemplo, la digitalización como causa de la revolución del sector. De esta manera, admiten que las redes sociales han proporcionado al hotel más información sobre las opiniones de los clientes o las demandas de los consumidores que cualquier otro sistema de análisis del mercado. Dicha información es manejada por el hotel como instrumento para fomentar la fidelización, como ya se ha comentado, introducir cambios que son demandados por los clientes o suprimir aquellos que no son bien recibidos.

Todos están de acuerdo en que las redes sociales han afectado y proporcionado nuevas oportunidades al sector turístico, en general, y al hotelero, en particular, y todos están, asimismo, de acuerdo que ha sido una incidencia positiva. 


\subsection{Valoración de las redes sociales (ventajas y desventajas)}

Esta categoría ha sido dividida en las ventajas y las desventajas que las redes sociales proporcionan al sector hotelero. En la mayoría de las respuestas ha habido unanimidad, siempre contando con puntualizaciones y matices cambiantes.

Ventajas:

- Atención personalizada, permitiendo captar y fidelizar clientes.

- Permite dirigir el mensaje en función de las características de los usuarios.

- La capacidad de llegar a los clientes que se interesen por la oferta de cada hotel. Esto se combina con la posibilidad de acceso a un enorme número de clientes potenciales y una gran capacidad para el contacto directo.

- Generalmente el uso de las redes sociales tiene unos costes muy reducidos respecto a medios promocionales y publicitarios tradicionales, tanto respecto a la inversión de las campañas como en el mantenimiento de las mismas. Además, es posible segmentar dichas campañas a un precio, asimismo, reducido.

- Todo ello lleva a una de las más importantes ventajas que tienen las redes sociales para los hoteles: la visibilidad. Los hoteles son visibles en las redes a través de mensajes de texto, imágenes y videos, en los que se puede obtener información del hotel y contemplar las habitaciones, salones, dependencias, etc. Es muy fácil que cualquier persona, en cualquier parte del mundo, se haga una idea muy clara de lo que le ofrece el hotel y cómo sería su estancia en el mismo.

En síntesis, contribuyen a mejorar la experiencia hotelera y hacen más eficiente la gestión del servicio al cliente. Debido a esto, obliga a los hoteles a ser mejores y más transparentes con las actividades que se llevan a cabo, es decir, impulsa a la constante satisfacción de los clientes.

Desventajas:

- La principal desventaja son las críticas que aparecen en las redes sobre el hotel. El problema se plantea porque las críticas son muy difíciles de controlar en las redes sociales, así una crítica puede mantenerse mucho tiempo en la red aun cuando el problema esté solucionado. La mejor alternativa a estas críticas es mejorar la imagen del hotel y revertir las criticas malas con otras buenas.

- Sobre lo especificado anteriormente de considerar una ventaja que las redes proporcionen información e interactuación a tiempo real, también puede ser considerado una desventaja por cuanto esta presencia continua obliga a mantener una gestión constante de 24 horas al día 7 días a la semana, como indican varios de los entrevistados.

- Por último, consideran de especial relevancia tener a un personal cualificado, ya que si las redes sociales y el entorno digital no son gestionados eficientemente puede causar grandes perjuicios a la marca hotelera. 


\subsection{Prospectiva de las redes sociales}

La opinión general es que el futuro se encuentra en las redes sociales. Muy probablemente, en opinión de prácticamente todos los participantes, tanto a corto como a largo plazo las redes serán el principal medio de comunicación, promoción e información de los hoteles.

Todos los entrevistados han valorado que en un futuro las redes sociales serán la fuente que mueve la promoción de los hoteles, puesto que irán evolucionando y estarán muy involucradas en el mundo digital. De este modo, las redes sociales se integrarán de manera importante en la parte operativa para hacer reservas y para obtener datos sobre la experiencia de los clientes, la cantidad de usuarios existentes y su opinión sobre los servicios recibidos.

Además, varios de ellos consideran que la evolución de las nuevas tecnologías en el ámbito digital jugara un papel crucial y que todo va a ir encaminado a mejorar la experiencia del usuario.

\section{CONCLUSIONES}

A través del análisis de la información proporcionada se ha permitido conocer los aspectos esenciales en la utilización de las redes sociales en el sector hotelero. A continuación, se determinan las principales conclusiones:

Los hoteles analizados utilizan las redes sociales esencialmente para incrementar sus reservas de plazas libres, tratando de que los usuarios se interesen por los servicios hoteleros a través de una mayor difusión de los mismos. Es posible (y deseable) llevar a cabo distintos tipos de estrategias teniendo en cuenta la red social en la que se intervenga o el público objetivo a la que se dirige, pero, en general, lo que pretenden conseguir es una mayor presencia del hotel en las redes, el mantenimiento de las mismas y lograr el mejor posicionamiento posible. El análisis realizado puso de manifiesto de forma clara el desempeño de las siguientes estrategias: dirigirse a segmentos de la población y al mismo tiempo incidir en un amplísimo entorno; realizar lanzamientos estacionales y ofrecer promociones en función de los días de la semana. Respecto a la estrategia de las publicaciones destacar que, aunque coinciden con la literatura en señalar la importancia de generar contenido de calidad, ninguno de los entrevistados especificó la importancia de la utilización de imágenes y videos como especificaron los autores Zavala y Estrada (2017). De la misma manera, los entrevistados sí destacaron la utilización de publicaciones promocionales pese a que autores como Leung et al. (2017) la consideren en general poco efectivas para el sector hotelero. En definitiva, se desarrollan estrategias de captación de clientes y fidelización de manera permanente y dirigida. Además, un elemento que está presente habitualmente consiste en buscar una mayor interacción entre el hotel y los clientes de manera que estos puedan informarse y resolver sus dudas.

Todos los responsables de los hoteles analizados coinciden en que la mejor apuesta es Facebook y, en segundo lugar, Twitter, como redes generalistas, aunque para decidir las redes sociales en las que se debe intervenir es importante tener en cuenta los objetivos generales de marketing y la contribución de cada red social en el negocio. Este aspecto coincide con lo especificado por Martín Arteaga (2016) y Piñeiro (2012) los cuáles consideran más adecuado 
centrarse en pocas comunidades que los hoteles puedan atender mejor de forma más concreta. También coincide con el estudio de Leung et al. (2017) al señalar a Facebook como la red social con mayores posibilidades en el sector hotelero. Además, las redes especializadas en el sector turístico se suelen tener en cuenta para conocer la opinión de los clientes. Al mismo tiempo, coinciden con el estudio de Bueno et al. (2017) en afirmar que la utilización de las redes sociales pasa por promocionar, informar, interactuar, fidelizar y captar tanto a los clientes actuales como los potenciales. Mediante las redes sociales se representa la imagen de la empresa y condiciona las reservas, puesto que la mayoría de las personas consultan las redes antes de decidir su estancia en un determinado hotel. Respecto a las herramientas utilizadas en la gestión de redes sociales hay más discrepancia entre los entrevistados. La mayoría de los gestores utilizan Hootsuite para la gestión de diferentes redes sociales, aunque algunos prefieren usar otras herramientas de menor coste como Review Pro. Otros, actualmente, no usan ninguna herramienta en la gestión, pero estudian la posibilidad de usarlas en el futuro.

Por otra parte, hay unanimidad en las ventajas que encuentran los entrevistados en el uso de las redes sociales. Se considera de especial relevancia fidelizar al cliente actual del hotel y captar a los potenciales. Otra de las ventajas de las redes sociales es la capacidad de hacer llegar la oferta y las características del hotel a un gran número de clientes potenciales tal como se especifica en el estudio de León (2016), considerando, por tanto, que es difícil encontrar un medio tan barato y que tenga la posibilidad de llegar a un enorme número de usuarios. También destacan los entrevistados la importancia en conseguir una mejora de la imagen y reputación online, elementos esenciales en el negocio hotelero tal como se especifica en los estudios de Ortiz y González (2014) y López (2010). Otras ventajas destacadas son: la visibilidad, la facilidad de acceder a la información y la posibilidad de tener una mejor comunicación, relación e interacción con los usuarios. Respecto a las desventajas son: las críticas que pueden aparecer sobre el hotel en las redes ya que son muy difíciles de controlar y de anular, aun cuando se resuelvan los problemas que las provocaron. La segunda desventaja es más bien una deficiencia de la gestión, se trata de los costes de imagen que acarrearía en el hotel una intervención en la red deficiente, mal redactada y descuidada. Esto hace corroborar lo especificado por los autores García et al. (2017) y Majó et al. (2018), que consideran esencial un personal experto y cualificado en la gestión de las redes sociales y que atienda eficientemente los comentarios de los usuarios.

El proceso de comunicación ha cambiado, siendo actualmente las redes sociales el principal medio por el que los usuarios prefieren interaccionar y comunicarse con el hotel. La tendencia del marketing actual es dirigirse a un gran universo de posibles clientes, pero con la posibilidad de hacerlo de manera segmentada, intentando llegar individualmente a los mismos. Lo que se deduce de todas las respuestas es que el futuro de la comercialización y comunicación hotelera en todas sus variantes pasa por las redes sociales, hasta el punto que, en el corto/medio plazo, la mayor parte de todo el proceso por el que transcurre el negocio hotelero será, fundamentalmente, a través de estas plataformas. De este modo, el futuro apunta a un predominio de las redes sociales para la promoción, el análisis y la mejora del sector hotelero tal como se apunta en los estudios de Ristova y Dimitrov (2019) y Martins et al. (2018). A partir del avance de las tecnologías de la información y la comunicación, se vislumbra a las redes sociales como una de las principales herramientas en la estrategia de marketing. 
También se destaca la importancia que tendrán las nuevas tecnologías de la comunicación como indican los estudios de Yim et al. (2019) y Linton y Kwortnik (2019), aunque sin hacer mención de manera expresa a los dispositivos móviles

\section{LIMITACIONES DEL ESTUDIO}

Respecto a los resultados obtenidos deben tenerse en cuenta las siguientes limitaciones. En el estudio cualitativo las entrevistas fueron realizadas a 10 gestores de las redes sociales. Si bien la muestra se considera representativa, debido a la diversidad y heterogeneidad del sector hotelero podría obtenerse más información con un mayor número de participantes. Igualmente, no se han tenido en cuenta las relaciones entre los hoteles independientes y cadenas hoteleras ya que para alcanzar el objetivo de este estudio no se ha precisado de esta distinción. No obstante, para futuros estudios sería interesante plantear otros objetivos que tuvieran en cuenta la distinción de estas variables.

\section{FUTURAS LÍNEAS DE INVESTIGACIÓN}

Las contribuciones de este estudio sugieren incipientes líneas de investigación. A continuación, se proponen algunas consideraciones que pueden ser tenidas en cuenta para futuras líneas:

- Además de la información cualitativa proporcionada por los gestores de las redes sociales analizada en esta tesis, sería de interés obtener información cuantitativa para conocer en qué medida estos trabajadores desempeñan las diferentes actividades en su puesto de trabajo.

- Resultaría interesante realizar un análisis más profundo sobre la intervención de uno o varios hoteles en las redes sociales y en el entorno digital a través del método del caso. A través de un estudio más pormenorizado de un hotel o varios hoteles se podrían obtener una serie datos proporcionados por los propios establecimientos que no se han podido tener en cuenta en esta investigación por estar solamente disponible para los administradores de las páginas.

- A lo largo de los años han ido surgiendo nuevas tecnologías en el entorno digital que van obteniendo relevancia por parte de los usuarios, como es el caso del marketing móvil y la realidad virtual. En este sentido, sería interesante estudiar los beneficios y utilidades que obtienen los usuarios en el uso de estas herramientas

\section{BIBLIOGRAFÍA}

Aburrá. (2016): "La importancia de las comunicaciones en el sector hotelero". Recuperado el 2 de febrero de 2017 en: http://www.aburracds.com/campanas-y-notas-de-interes/33-la-importancia-de-las-comunicaciones-en-el-sector-hotelero

Ahani, A., Nilashi, M., Ibrahim, O., Sanzogni, L., y Weaven, S. (2019). “Market segmentation and travel choice prediction in spa hotels through tripadvisor's online reviews". International Journal of Hospitality Management, 80, 52-77. 
Alamäki, A., Pesonen, J. y Dirin, A. (2019). "Triggering effects of mobile video marketing in nature tourism: Media richness perspective". Information Processing \& Management, 56(3), 756-770.

Banyai, M. y Glover, T. D. (2012). "Evaluating research methods on travel blogs". Journal of Travel Research, 51(3), 267-277.

Barcelos, R. H., Dantas, D. C., y Sénécal, S. (2019). "The tone of voice of tourism brands on social media: Does it matter?". Tourism Management, 74, 173-189.

Breda, Z., Pacheco, C. y Dinis, G. (2019). "Future trends in the hospitality industry: an analysis from the consumers'point of view". Tourism in South East Europe..., 5, 139-162.

Bueno, M. Á. B., Meroño, M. C. P. y Piernas, J. M. P. (2017): "Las redes sociales aplicadas al sector hotelero". International journal of scientific management and tourism, 3(2), 131-153.

Camara, A. L. D. M. S. (2019). "A influência do instagram no consumidor de viagens: Uma análise da Voyage Turismo".

Caro, J. L., Luque, A. y Zayas, B. (2015). “Nuevas tecnologías para la interpretación y promoción de los recursos turísticos culturales". Pasos. Revista de Turismo Y Patrimonio Cultural, 13(4), 931-945.

Carpio Maraza, A., Hancco Gomez, M. S., Limache, C., Magno, A. y Flores Mamani, E. (2019). "Estrategias del marketing viral y el posicionamiento de marca en los restaurantes turísticos de la Región de Puno”. Comuni@cción, 10(1), 70-80.

Cascales, G., Cortés, T. y Galmés, M. (2015): “Social media y estrategias de comunicación de las redes sociales en el sector hotelero de la Comunidad de Madrid". Fonseca, Journal of Communication, 11, 249-282.

Chaves, C. R. (2005): "La categorización un aspecto crucial en la investigación cualitativa". InvestigiumIRE, 6(1), 113-118.

Chen, C., Zhang, K. Z., Gong, X., Zhao, S. J., Lee, M. K. y Liang, L. (2017). “Understanding compulsive smartphone use: An empirical test of a flow-based model". International Journal of Information Management, 37(5), 438-454.

Chen, Y. S. y Wu, S. T. (2019). "Social networking practices of Viennese coffeehouse culture and intangible heritage tourism". Journal of Tourism and Cultural Change, 17(2), 186-207.

Destors, J. (2010): “Ante la efectividad del boca a boca ¿Dónde queda la tecnología?". Tecno Hotel. Gestión Hotelera, 447, 30-31.

Diana-Jens, P. y Ruibal, A. R. (2015): "La reputación online y su impacto en la política de precios de los hoteles". Cuadernos de Turismo, (36), 129-155.

Ellingson, L. L. (2013): "Analysis and representation across the continuum". Collecting and interpreting qualitative materials, 413-445.

Espigares-Jurado, F., Muñoz-Leiva, F., Correia, M. B., Sousa, C. M., Ramos, C. M. y Faísca, L. (2020). "Visual attention to the main image of a hotel website based on its position, type of navigation and belonging to Millennial generation: An eye tracking study". Journal of Retailing and Consumer Services, 52, 101906.

Four Pillars Hotels (2015): "The Impact of Social Media Within The Hospitality Industry" Recuperado el 24 de septiembre de 2020 en: http://www.iresort.net/en/ the-impact-of-social-media-within-the-hospitality-industry/ 
García, G. C., Moraleda, L. F. y Curiel, J. D. E. (2017): "La interacción de los hoteles con las redes sociales: un análisis de los hoteles de cuatro estrellas de la Comunidad de Madrid (España)". Cuadernos de Turismo, (39), 131-148.

Hai-Jew, S. (2014): Enhancing qualitative and mixed methods research with technology. IGI Global. Kansas (USA).

Hemar-Nicolas, V., Ezan, P., Gollety, M., Guichard, N. y Leroy, J. (2013): "How do children learn eating practices? beyond the nutritional information, the importance of social eating". Young Consumers, 14(1), 5-18.

Hernández Sampieri, R., Fernández Collado, C. y Baptista Lucio, P. (2010): Metodología de la investigación. México DF.

Huang, C. D., Goo, J., Nam, K., \& Yoo, C. W. (2017). "Smart tourism technologies in travel planning: The role of exploration and exploitation". Information \& Management, 54(6), 757-770.

i Agustí, D. P. (2018). "Characterizing the location of tourist images in cities. Differences in user-generated images (Instagram), official tourist brochures and travel guides". Annals of Tourism Research, 73, 103-115.

IAB Spain (2019). "Estudio anual de redes sociales". Recuperado el 2 diciembre de 2019 en: https://iabspain.es/estudio/estudio-anual-de-redes-sociales-2019/

Lee, S. A. (2018). "Enhancing customers' continued mobile app use in the service industry". Journal of Services Marketing.

Lehtonen, M. (2000): The cultural analysis of texts. Sage. London.

Lemon, K. N. y Verhoef, P. C. (2016). "Understanding customer experience throughout the customer journey". Journal of marketing, 80(6), 69-96.

León, M. L. (2016): "Cinco maneras en las que las redes sociales cambiaron al turismo". Recuperado el 27 de marzo de 2017 en: http://blogs.unitec.mx/ vida-universitaria/5-maneras-en-las-que-las-redes-sociales-cambiaron-al-turismo

Leung, X. Y., Bai, B. y Erdem, M. (2017): "Hotel social media marketing: A study on message strategy and its effectiveness". Journal of Hospitality and Tourism Technology, 8(2), 239-255.

Leva, M. y Ziliani, C. (2018). "Mapping touchpoint exposure in retailing: Implications for developing an omnichannel customer experience". International Journal of Retail and Distribution Management, 46(3), 304-322.

Linton, H. y Kwortnik, R. J. (2019). "Mobile usage in travel: bridging the supplier-user gap". International Journal of Contemporary Hospitality Management.

López, E. (2010): “La reputación corporativa on line aplicada al sector turístico español”. AEIC 2010 Málaga.

Majó, J., Moya, D. y Vall-Ilosera, L. (2018): “Impacto de las redes sociales en los ingresos de los hoteles en Colombia, Ecuador y Perú". Revista Facultad de Ciencias Económicas: Investigación y Reflexión, 26(1), 147-162.

Martín, M. (1995): "El análisis de contenido en la investigación sobre comunicación". Periodística, 8, 67-74.

Martín, R. y Arteaga, M. (2016): "La presencia en la web de los establecimientos hoteleros de la isla de Tenerife". Papers de turismo, 59, 36-61. 
Martins, B. I., de Albuquerque, L. C. E. y Neves, M. (2018). “Instagram Insights: Ferramenta de Análise de Resultados como Nova Estratégia de Marketing Digital". Intercom, 1, 1-13.

Mirzaalian, F. y Halpenny, E. (2019). "Social media analytics in hospitality and tourism". Journal of Hospitality and Tourism Technology.

Muñoz-Leiva, F., Hernández-Méndez, J. y Gómez-Carmona, D. (2019). “Measuring advertising effectiveness in Travel 2.0 websites through eye-tracking technology". Physiology \& behavior, 200, 83-95.

Narangajavana Kaosiri, Y., Callarisa Fiol, L. J., Moliner Tena, M. A., Rodriguez Artola, R. M. y Sanchez Garcia, J. (2019). "User-generated content sources in social media: A new approach to explore tourist satisfaction". Journal of Travel Research, 58(2), 253-265.

Ong, B. S. (2012): "The perceived influence of user reviews in the hospitality industry". Journal of Hospitality marketing \& Management, 21(5), 463.

Ortiz, L y González, R. (2014): "Las redes sociales como herramienta de mejora de la experiencia turística: una aplicación al sector hotelero". Revista Iberoamericana de Turismo, 4(1), 16-34.

Piñeiro, M. (2012): “¿Cómo conseguir la mejor imagen de marca con las redes sociales?”. Recuperado el 13 de septiembre de 2015 en: http://www.concepto05.com/2012/04/ como-conseguir-la-mejor-imagen-de-marca-con-las-redes-sociales/

Rhodes, J., Bergstrom, B., Lok, P. y Cheng, V. (2014): “A framework for stakeholder engagement and sustainable development in MNCs". Journal of Global Responsibility, 5(1), 82-103.

Rickly-Boyd, J. M. (2013): "Dirtbags Mobility, community and rock climbing as performative of identity. Lifestyle Mobilities". Intersections of Travel, Leisure and Migration, 51-64.

Ristova, C. y Dimitrov, N. (2019). "The value of social media as digital tool in hospitality". International Journal of Information, Business and Management, 11(3), 155-162.

Ristova, C., y Dimitrov, N. (2019). "The value of social media as digital tool in hospitality". International Journal of Information, Business and Management, 11(3), 155-162.

Rodríguez, G., Gil, J. y García, E. (1999): Metodología de la investigación cualitativa. Ediciones Aljibe. Málaga.

Santos-Corrada, M. D. L. M., Flecha, J. A., Lopez, E. y Dones, V. (2019). “Millenials: las gratificaciones generadas por el uso de snapchat y su impacto en la interacción con contenidos de marca". Estudios Gerenciales, 35(152), 259-270.

Sociales, C. y Chaves, F. F. (2002): "El análisis de contenido como ayuda metodológica para la investigación". Ciencias sociales, 96, 35-53.

Tsiakali, K. (2018). "User-generated-content versus marketing-generated-content: Personality and content influence on traveler's behavior". Journal of Hospitality Marketing \& Management, 27(8), 946-972.

Vargas, I. (2012): "La entrevista en la investigación cualitativa: nuevas tendencias y retos". Revista Calidad en la Educación Superior, 3(1), 119-139.

Wichels, S. (2016): "Cómo las redes sociales están cambiando la comunicación hotelera". Revista Internacional de Tecnología, Ciencia y Sociedad, 3(2).

Woolthuis, R. K., Hillebrand, B. y Nooteboom, B. (2005): “Trust, contract and relationship development". Organization studies, 26(6), 813-840.

Yim, J., Ganesan, S. y Kang, B. H. (2019). "Location-Based Mobile Marketing Innovations 2018". Mobile Information Systems, 2019. 
Zavala, A. M. M. y Estrada, I. C. (2016): "Redes sociales: Herramienta de Marketing Internacional en el sector hotelero". El Periplo Sustentable, (31).

Zavala, A. M. M. y Estrada, I. C. (2017): “Uso de las redes sociales digitales en empresas hoteleras en la ciudad de Tijuana, Baja California". Revista Nacional de Administración, 8(1), 46-60. 